\title{
Morphology and Micromechanics of Polymers highlights
}

\section{Merseburg (Germany), 27 September to 1 October 1998}

$M$ icromechanical processes-which $M$ are the processes on mesoscopic, microscopic and nanometer scales that occur inside a material in response to an external loading-can be studied using different techniques. This conference was one of the first international conferences covering this new and interesting field of micromechanics.

We heard about new developments in electron microscope techniques for direct imaging of the crystal structure (morphology) and micromechanical mechanisms in polymers. Environmental scanning electron microscopy has emerged as a new technique for investigating the morphology of polymer blends -in contrast to conventional scanning electron microscopy samples do not need to be coated with a conducting layer. Scanning force microscopy has shown considerable potential as an imaging tool for the study of surface morphologies from nanometer

are you going to...?

\section{Applications}

\section{of Physics}

\section{in Financial}

\section{Analysis}

\author{
15 to 17 July \\ Dublin, Ireland
}

a statistical \& nonlinear

physics conference, it will encourage physicists and financial experts to discuss the way financial markets can be modelled to micrometer scales as well as for real in situ studying of micromechanical processes. For example, in a heterogeneous semicrystalline polymer blend the step-by-step increase in elongation of an area under a scanning force microscope reveals the different micromechanical behaviour of the soft-amorphous particles compared to the stiff lamellar matrix. Xray scattering, using synchrotron radiation sources, and micro-and nano-indentation measurements at surfaces have become powerful methods for following, in real time, morphological changes in polymers. And magnetic resonance imaging has been shown to be an interesting technique for providing information about polymer morphology.

On the basis of the detailed knowledge of micromechanics, a better understanding of structure-property correlations becomes possible.

At this conference special emphasis was given to recent advances in the understanding of crystallization, particularly the growth of spherulites (rounded polycrystals) in polymers. The formation of cavities in rubber particles is now accepted as an important factor in toughening in rubber-modified polymers. New results in experimental detection and in modelling aspects were reported. Increasing attention has been paid to the morphological investigation of di-, triand starblockcopolymers in the last few years, revealing a wide variety of new morphologies. The modification of thermoset blends and composites by introducing a high performance thermoplastic having a "morphology gradient" has emerged as a new method for improving the fracture toughness of these materials. Crazing (the formation of very fine nanometre cracks) in glassy polymers has been studied for many years; latest results show that the parameters which are important in amorphous polymers also influence crazing in semicrystalline thermoplastics, although additional parameters emerge in the latter, resulting from the lamellar and spherulitic morphology.

The authors are Goerg H. Michler, Chairman of the Organizing Committee, and Francisco J. Baltá Calleja, Chairman of EPS Macromolecular Board

\section{the subject}

If the workshops organized every two years on this subject are anything to go by, this conference is likely to be the most exciting of the year.

How should we analyse market fluctuations (or financial risk, or option pricing)? For example: what is the best way to program a computer to simulate the pricing fluctuations of real markets?

Among the participants will be econophysicists, those physicists who have turned their expertise in statistical physics towards the behaviour of financial markets. They are not shy when discussing each other's models and methods (said to be a characteristic of an emerging discipline) so topics are going to be hotly debated. And there will be the added bonus of being able to discuss freely with mathematicians and financial experts, too.

\section{registration}

Christine Bastian, EPS Conferences

34 rue Marc Seguin, BP 2136

F-68060 Mulhouse Cedex, France

$t e l+33389329440$ fax +33389329449

email eps.conf@univ-mulhouse.fr

Website www.nbi.dk/APFA

early payment deadline 14 May

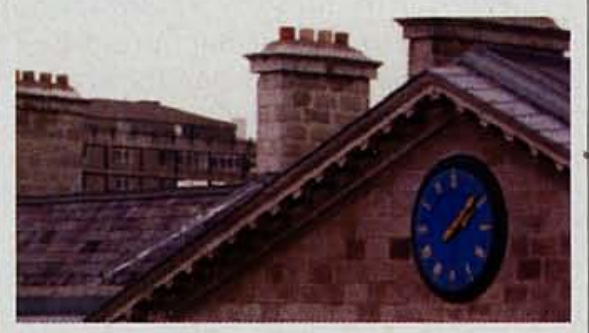

the place

Trinity College is perfectly situated for the evening: the Temple Bar district close to college is full of restaurants and lively pubs. In the daytime head for the Book of Kells in the Old Library on college campus (colourful New Testament gospels dated $800 \mathrm{AD}$ ). Upstairs there is a stunning 18 thcentury library with barrel-vaulted ceiling.

\section{where to buy your bus ticket}

The airport is 12 kilometres north of Dublin centre. Plan to arrive the morning of 15 July. A taxi into town will cost about $£ 13$ (Irish pounds). To catch an Airlink bus turn left when leaving the airport. Ask the driver to tell you when you reach $0^{\prime}$ Connell Street. From here, walk south across the river to reach Trinity College. The bus takes 30 minutes and costs $£ 2.50$. You can buy your ticket from the driver as you get on. 